\title{
Differences in autonomic nerve function in patients with silent and symptomatic myocardial ischaemia
}

\author{
Carl F Shakespeare, Demosthenes Katritsis, Alec Crowther, Ian C Cooper,
} John D Coltart, Michael M Webb-Peploe

\begin{abstract}
Background-Autonomic neuropathy provides a mechanism for the absence of symptoms in silent myocardial ischaemia, but characterisation of the type of neuropathy is lacking.

Aim-To characterise and compare autonomic nerve function in patients with silent and symptomatic myocardial ischaemia.

Methods and results-The Valsalva manoeuvre, heart rate variation (HRV) in response to deep breathing and standing, lower body negative pressure, isometric handgrip, and the cold pressor test were performed by patients with silent $(n=25)$ and symptomatic $(n=25)$ ambulatory ischaemia and by controls $(n=21)$. No difference in parasympathetic efferent function between patients with silent and symptomatic ischaemia was recorded, but both had significantly less HRV in response to standing than the controls $(p<0.005$ for silent and $p<0.01$ for symptomatic). Patients with silent ischaemia showed an increased propensity for peripheral vasodilatation compared with symptomatic patients $(p<0.02)$ and controls $(p<$ 0.04). Impaired sympathetic function was found in patients with pure silent ischaemia $(n=4)$ compared with the remaining patients with silent ischaemia whose pain pathways were presumed to be intact.

Conchusions-Patients with silent ischaemia and pain pathways presumed to be intact have an enhanced peripheral vasodilator response, and if this applied to the coronary vasculature it could provide a mechanism for limiting ischaemia to below the pain threshold. Patients with pure silent ischaemia have evidence of sympathetic autonomic dysfunction.
\end{abstract}

Cardiac Department, St Thomas' Hospital, London

C F Shakespeare

D Katritsis

A Crowther

I C Cooper

J D Coltart

M M Webb-Peploe

Correspondence to:

Corresplent

Department of Cardiology,

Royal London Hospital,

Royal London Hospital, Whitech.

Accepted for publication 5 July 1993

Cardiac autonomic afferent nerves were first found almost a century ago. ${ }^{12}$ Parasympathetic and sympathetic afferents are thought to convey sensory data from the heart to modulate homoeostasis and regulate cardiac function through cardiocardiac reflexes. ${ }^{3-5}$ In humans, sympathetic afferent nerves are also thought to convey the symptom of angina in patients with ischaemic heart disease, and evidence for this is provided by finding that surgical rhizotomy (cervical sympathectomy) abolished angina in patients with ischaemic heart disease. ${ }^{6}$

Silent ischaemia can be purely silent, can occur after myocardial infarction, or can coexist with symptomatic ischaemia. ${ }^{7}$ Postulated mechanisms of silent ischaemia include an altered pain threshold, ${ }^{8}$ subthreshold ischaemia insufficient to cause pain, and dysfunction of cardiac autonomic afferent nerves. In patients with pure silent ischaemia, autonomic afferent dysfunction is likely. This is supported by the fact that patients with diabetes mellitus and autonomic neuropathy have a high incidence of pure silent myocardial ischaemia ${ }^{10}$ although the type of neuropathy in such patients was not described. Afferent dysfunction is less likely in patients with previous symptoms in whom pain pathways are likely to be intact.

The aim of the study was to characterise and compare autonomic nerve function in patients with silent and symptomatic myocardial ischaemia and in controls.

Patients and methods SUBJECT SELECTION

After approval by the ethics committee controls and patients with significant angiographic coronary artery disease $(\geqslant 50 \%$ narrowing in one or more major coronary arteries) gave informed consent. All patients and controls were men. Patients were excluded on the basis of poor physical health, myocardial infarction within the last month, unstable angina, valvar disease, heart failure, antiarrhythmic medication, or baseline electrocardiographic abnormalities that precluded accurate Holter analysis of ischaemia. The controls had no history suggestive of ischaemic heart disease and had a negative exercise test but did not undergo thallium scintigraphy, ambulatory monitoring, or cardiac catheterisation.

\section{ASSESSMENT OF MYOCARDIAL ISCHAEMIA} angiographic ejection fraction were reported by a consultant without knowledge of the patients' participation in the study. Patients with a reduced ejection fraction $(<35 \%$ by planimetry) were excluded. Patients had stopped taking $\beta$ blockers for 48 hours, and other antianginal drugs for 12 hours before 
the exercise test, thallium scan, ambulatory monitoring, and autonomic function tests. A positive symptom limited Bruce protocol exercise test was defined by $\geqslant 2 \mathrm{~mm} S T$ depression $80 \mathrm{~ms}$ after the J point. During exercise scintigraphy $75 \mathrm{mBq}$ thallous chloride (New England Ltd) was injected at peak exercise, then planar images were taken for 300 seconds in the left lateral, left anterior oblique $\left(45^{\circ}\right)$, and anterior positions. Rest images were taken four hours later. Scintigrams were reported independently by two experts in nuclear medicine without knowledge of the patients' participation in the study, and any differences were resolved by consensus. Patients underwent 24 to 48 hours of ambulatory ST segment monitoring with a two channel solid state digital e-ram recorder (Reynolds Medical). Electrodes were placed in the V5 and modified lead III positions. Patients were instructed to keep as active as possible, used an anginal diary, and pressed an electronic marker on the e-ram at the onset of an anginal episode. The recording was analysed visually with a Pathfinder 3 analyser. An ischaemic episode was defined as $\geqslant 1 \mathrm{~mm}$ ST depression occurring $80 \mathrm{~ms}$ after the J point and having a duration $\geqslant$ one minute. An interval of one minute was required between two successive episodes of ST depression to constitute two separate episodes.

Patients were allocated to one of two groups on the basis of detectable ambulatory ischaemia. Group 1 (silent) consisted of patients who only had ambulatory episodes of symptom free ST depression, and group 2 (symptomatic) consisted of patients who had symptomatic episodes of ST depression. Group 2 included patients who also had episodes of symptom free ST depression interspersed with symptomatic episodes. Group 1 was further subgrouped into patients with pure silent ischaemia in whom autonomic afferent dysfunction is likely and the remaining patients with silent ischaemia who had previously intact sensory nerves.

\section{AUTONOMIC FUNCTION TESTS}

Patients and controls underwent autonomic nerve tests in one session between 10.00 and 15.00. The Valsalva manoeuvre and heart rate variation response to standing and deep breathing were used as tests of parasympathetic efferent function. ${ }^{11}$ In the Valsalva manoeuvre the seated subject blew into a sphygmomanometer and maintained the mercury meniscus at $40 \mathrm{~mm} \mathrm{Hg}$ for $12 \mathrm{sec}-$ onds, then released. Cuff blood pressure was measured before blowing and on release. The ratio of the maximum $R R$ interval on release to the minimum $R R$ interval during two manoeuvres was calculated and the greater ratio recorded. Between each test the subject was rested for 15 minutes or longer to restore baseline heart rate and blood pressure. Heart rate variation on standing was measured by calculating the ratio of the $R R$ interval at the 30 th and 15 th beat after standing. Heart rate variation during deep breathing was then measured: subjects inspired and expired deeply six times for one minute, the maximal inspiratory and minimal expiratory $R R$ intervals were recorded for each breathing cycle, averaged for the six cycles, and an expiratory to inspiratory ratio calculated.

The subject then performed isometric handgrip to assess peripheral vasodilation, which probably reflects a combination of sympathetic $\beta_{2}$ and atropine sensitive cholinergic effects. ${ }^{1213}$ Measurements of heart rate, mean arterial pressure (cuff), plethysmographic forearm blood flow (FBF), and vascular resistance (FVR) were made before and during two minutes of grip at $75 \%$ of maximum voluntary contraction with a hand held dynamometer (Model EM-50 Psytech, Denmark).

The lower body negative pressure (LBNP) test was then used to test parasympathetic afferent function. At low levels of LBNP there is no change in arterial pressure or heart rate, so the activity of the cardiopulmonary afferents can be determined without involvement of other baroreceptors. ${ }^{14} \mathrm{~A}$ sympathetic efferent $a$ mediated vasoconstrictor response is measured, ${ }^{15} 16$ but provided the efferent limb of the pathway can be shown to be intect, it can be used to determine parasympathetic afferent function. The subject was placed in a chamber sealed below the ribs and $-10 \mathrm{~mm} \mathrm{Hg}$ suction applied for one minute. Heart rate, mean arterial pressure, FBF, and FVR were recorded before and after one minute of suction.

The cold pressor test was then used as a test of sympathetic efferent function: ${ }^{17} 18$ cardiac $\beta_{1}$ adrenoreceptor function was assessed by changes in heart rate, and peripheral $a$ adrenoreceptor function was assessed by changes in FBF and FVR. Measurements of FBF, FVR, mean arterial pressure, and heart rate were made before and after one minute of immersion of the forearm in ice.

\section{PLETHYSMOGRAPHIC MEASUREMENTS}

We used a calibrated mercury in rubber strain gauge plethysmograph (Medimatic SP 2, Denmark). A venous cuff was placed above the right elbow and the strain gauge around the widest part of the right forearm. A hand cuff was not used as hand circulation was previously shown not to affect measurements of flow, and caused discomfort when at more than systolic pressure. ${ }^{19}$ With the arm semipronated, the venous cuff was inflated to a pressure of $60 \mathrm{~mm} \mathrm{Hg}$ to occlude venous outflow. Arterial inflow is unimpeded and causes forearm swelling and distension of the strain gauge. The strain gauge forms one arm of a balanced Wheatstone bridge that becomes unbalanced on distension due to a change in resistance and causes a current deflection on a moving chart recorder. The initial rate of swelling is directly related to arterial inflow in the first few seconds and the measurement of FBF (in $\mathrm{ml} / 100 \mathrm{ml} / \mathrm{min}$ ) derived by the Greenfield method. ${ }^{20}$ Forearm vascular resistance is derived from dividing mean arterial pressure by FBF, and is expressed as $\mathrm{mm} \mathrm{Hg} / \mathrm{ml} / 100 \mathrm{ml} / \mathrm{min}$. 
STATISTICAL ANALYSIS

Paired and unpaired Student's $t$ tests and $\chi^{2}$ tests were used appropriately. All values are expressed as mean (SEM)

\section{Results}

PATIENT CHARACTERISTICS

Fifty patients were studied who had significant angiographic disease and evidence of ambulatory ischaemia. Twenty five were allocated to group 1 (with silent ischaemia), 25 to group 2 (with symptomatic ischaemia), and there were 21 controls. Table 1 summarises the patient characteristics. There were no hypertensive controls, and the number of hypertensive patients in both ischaemic groups was similar. The mean arterial pressure of the 17 hypertensive patients was higher than that of the remaining 33 ischaemic patients of both groups $(116.3(2 \cdot 4) \mathrm{mm} \mathrm{Hg} v 100.6(1.4) \mathrm{mm} \mathrm{Hg}$ $\mathrm{p}<0.0001)$. There were more patients taking

Table 1 Clinical characteristics

\begin{tabular}{lll}
\hline & Group 1 & Group 2 \\
\hline No & 25 & 25 \\
Age (yr, mean (SEM)) & $57 \cdot 6(1 \cdot 9)$ & $58 \cdot 2(1 \cdot 6)$ \\
History (n (\%)): & $8(32)$ & $16(64)$ \\
A & $7(28)$ & 0 \\
PIS & $4(16)$ & 0 \\
S & $6(24)$ & $9(36)$ \\
PIA & $8(32)$ & $9(36)$ \\
Hypertensive (n(\%)) & $9(25)$ & $16(64)$ \\
$\beta$ Blockers $(\mathrm{n}(\%))$ &
\end{tabular}

${ }^{\star} \mathrm{p}<0.05$ between groups 1 and 2 .

$A$, angina; PIA, postinfarction angina; PIS, postinfarction exercise silent ischaemia; $S$, pure silent ischaemia.

Table 2 Ischaemic characteristics

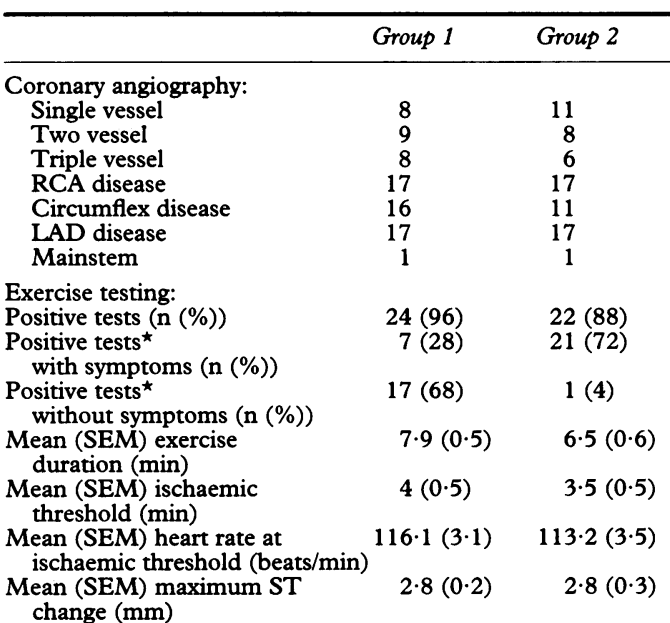

${ }^{\star} \mathrm{p}<0.001$ between groups 1 and 2 .

$\mathrm{LAD}$, left anterior descending artery; RCA, right coronary artery.

Table 3 Mean (SEM) Valsalva ratios and heart rate variation to deep breathing and standing

\begin{tabular}{llll}
\hline & Group 1 & Group 2 & Controls \\
\hline No of patients & 25 & 25 & 21 \\
Valsalva ratio & $1.26(0.03)$ & $1.25(0.03)$ & $1.36(0.06)$ \\
Valsalva rise in systolic pressure (mm Hg) & $26.7(4)$ & $27.3(5)$ & $22.7(3.4)$ \\
RR interval ratio (deep breathing)t & $1.23(0.03)$ & $1.17(0.03)$ & $1.22(0.02)$ \\
RR interval ratio (standing) $\dagger$ & $1.11(0.02)$ & $1.10(0.03)$ & $1.28(0.01)^{\star}$ \\
\hline
\end{tabular}

$\star_{p}<0.005$ between group 1 and controls, and $p<0.01$ between group 2 and controls. $\mathrm{tn}=17$ in group $1, \mathrm{n}=10$ in group $2, \mathrm{n}=18$ in the controls. $\beta$-blockers before the study in group 2 than group $1(\mathrm{p}<0.05)$. One patient in group 1 had diabetes mellitus.

\section{ISCHAEMIC CHARACTERISTICS}

There was no evidence of mitral regurgitation. The distribution and number of diseased vessels was not significantly different in groups 1 and 2 (table 2). Table 2 shows the characteristics of the exercise tests. Three patients in group 2 and one in group 1 had negative exercise tests. More patients had a symptomatic positive exercise test in group 2 than in group $1(p<0.001)$. In the patients with positive tests, the ischaemic threshold (time to $1 \mathrm{~mm} \mathrm{ST} \mathrm{depression),} \mathrm{heart} \mathrm{rate} \mathrm{at}$ the ischaemic threshold, and mean maximum ST depression were similar in both groups.

The number of fixed and reversible thallium defects in both ischaemic groups was similar. In group 1 , we found eight fixed defects in seven patients: one anterior, one inferior, one inferolateral, one septal, and three posterolateral; and 33 reversible defects in 22 patients: six anterior, three anterolateral, 16 inferior, two septal, three posterolateral, and three apical. In group 2 we found 10 fixed defects in seven patients: three anterior, three inferior, three posterolateral, and one apical; and 31 reversible defects in 22 patients: five anterior, 12 inferior, eight septal, and six posterolateral. The reversible defects were silent in 16 patients of group 1 and only one patient of group $2(p<0.001)$.

In group 1, the duration of ambulatory silent ischaemia was $21.0 \quad(4.5)$ minutes occurring for a mean of $2.5(0.4)$ episodes. In group 2 , the duration of ambulatory symptomatic ischaemia was $25.2(5.5)$ minutes occurring for $2.5(0.4)$ episodes. In group 2 , 17 patients had $25.3(5.5)$ minutes of ambulatory silent ischaemia occurring for a mean of $3.4(0.4)$ episodes, which was not significantly different from group 1 .

\section{PARASYMPATHETIC EFFERENT TESTS}

The Valsalva ratio in both ischaemic groups was lower than that of the controls but the difference was not significant (table 3 ).

Heart rate variation in response to deep breathing and after standing up was performed in 17 patients from group 1,10 patients from group 2, and 18 controls. Heart rate variation during deep breathing was similar in all groups. Heart rate variation on standing was significantly greater in the controls than both groups 1 and $2(p<0.005$ and $\mathrm{p}<0.01$ ).

\section{LOWER BODY NEGATIVE PRESSURE TEST}

In all three groups, mean arterial pressure did not change significantly during suction (table 4). The FBF decreased and FVR increased significantly during suction in each group, but the change in these variables did not differ significantly between the groups.

\section{COLD PRESSOR TEST}

In all groups, heart rate, mean arterial pressure, and FVR increased and FBF decreased 
Table 4 Mean (SEM) responses to one minute of $-10 \mathrm{~mm} \mathrm{Hg}$ lower body negative pressure

\begin{tabular}{lccc}
\hline & Group 1 & Group 2 & \multicolumn{1}{c}{ Controls } \\
\hline Baseline FBF & $4 \cdot 2(0 \cdot 4)$ & $4 \cdot 2(0 \cdot 5)$ & $3 \cdot 3(0 \cdot 2)$ \\
Change b-1 (\%) & $-22 \cdot 9(9 \cdot 3)^{\star \star \star}$ & $-39 \cdot 7(3 \cdot 4)^{\star \star \star}$ & $-26 \cdot 8(4 \cdot 4)^{\star \star \star}$ \\
Baseline FVR & $35 \cdot 2(4 \cdot 3)$ & $34(3 \cdot 7)$ & $34 \cdot 3(2 \cdot 5)$ \\
Change b-1 (\%) & $+71 \cdot 4(16 \cdot 2)^{\star \star}$ & $+80 \cdot 6(10 \cdot 5)^{\star \star \star}$ & $+55 \cdot 4(18 \cdot 7)^{\star \star}$ \\
Baseline MAP & $106 \cdot 5(2 \cdot 5)$ & $107(2 \cdot 4)$ & $100 \cdot 8(2 \cdot 2)$ \\
Change b-1 (\%) & $0 \cdot 4(0 \cdot 5)$ & $-0 \cdot 2(0 \cdot 6)$ & $+0 \cdot 2(0 \cdot 2)$ \\
Baseline heart rate & $67 \cdot 5(1 \cdot 7)$ & $64 \cdot 8(1 \cdot 7)$ & $65 \cdot 5(1 \cdot 9)$ \\
Change b-1 (\%) & $+10 \cdot 8(2 \cdot 3)$ & $+12 \cdot 0(2 \cdot 5)$ & $-1 \cdot 0(1 \cdot 0)$ \\
\hline
\end{tabular}

${ }^{\star} \mathrm{p}<0.05,{ }^{\star \star} \mathrm{p}<0.01,{ }^{\star \star \star} \mathrm{p}<0.001$. There was no significant difference in the change between the groups.

FBF, forearm blood flow ( $\mathrm{ml} / 100 / \mathrm{ml} / \mathrm{min})$; FVR, forearm vascular resistance $(\mathrm{mm} \mathrm{Hg} / \mathrm{ml}$ $100 \mathrm{ml} / \mathrm{min})$; MAP, mean arterial pressure $(\mathrm{mm} \mathrm{Hg}) ; \mathrm{b}-1$, baseline to one minute.

Table 5 Mean (SEM) responses to two minutes of forearm immersion in ice cold water

\begin{tabular}{|c|c|c|c|}
\hline & Group 1 & Group 2 & Controls \\
\hline No of patients & 25 & 25 & 21 \\
\hline $\begin{array}{l}\text { Baseline FBF } \\
\text { Change b-1 min } \\
\text { Change b-2 min } \\
\text { Change 1-2 min }\end{array}$ & $\begin{aligned} & 3 \cdot 2(0 \cdot 3) \\
- & 30 \cdot 4(7 \cdot 8)^{\star \star} \\
- & 21 \cdot 1(7 \cdot 2)^{\star} \\
+ & 11 \cdot 1(6 \cdot 9)^{\star \star}\end{aligned}$ & $\begin{aligned} & 3 \cdot 3(0 \cdot 3) \\
- & 39 \cdot 1(3 \cdot 7)^{\star \star \star} \\
- & 42 \cdot 3(12 \cdot 2)^{\star \star \star} \\
+ & 17 \cdot 4(6 \cdot 6)\end{aligned}$ & $\begin{aligned} & 3 \cdot 1(0 \cdot 2) \\
- & 31 \cdot 9(6 \cdot 8)^{\star \star \star} \\
- & 17 \cdot 2(6 \cdot 7)^{\star} \\
+ & 21 \cdot 2(6 \cdot 7)^{\star \star}\end{aligned}$ \\
\hline $\begin{array}{l}\text { Baseline FVR } \\
\text { Change b-1 } \\
\text { Change b-2 } \\
\text { Change 1-2 }\end{array}$ & $\begin{array}{l}41(3 \cdot 7) \\
+136 \cdot 3(30 \cdot 0)^{\star \star} \\
+96 \cdot 7(24 \cdot 5)^{\star \star} \\
-7 \cdot 8(5 \cdot 3)^{\star}\end{array}$ & $\begin{aligned} & 39 \cdot 3(3 \cdot 7) \\
&+ 171 \cdot 4(25 \cdot 5)^{\star \star \star} \\
& 118 \cdot 7(21 \cdot 7)^{\star \star \star} \\
&-4 \cdot 7(6 \cdot 7)^{\star}\end{aligned}$ & $\begin{array}{l}32 \cdot 3(2 \cdot 6) \\
+108 \cdot 6(19 \cdot 2)^{\star \star \star} \\
+58 \cdot 2(13 \cdot 7)^{\star \star \star} \\
-7 \cdot 7(5 \cdot 8)^{\star}\end{array}$ \\
\hline $\begin{array}{l}\text { Baseline MAP } \\
\text { Change b-1 } \\
\text { Change b-2 } \\
\text { Change 1-2 }\end{array}$ & $\begin{array}{l}107 \cdot 8(2 \cdot 5) \\
20 \cdot 7(2 \cdot 2)^{\star \star \star} \\
19 \cdot 4(2 \cdot 2)^{\star \star \star} \\
1 \cdot 4(1 \cdot 6)\end{array}$ & $\begin{array}{c}107.9(2.6) \\
23.4(2 \cdot 2)^{\star \star \star} \\
23.8(3 \cdot 7)^{\star \star \star} \\
0.6(0.9)\end{array}$ & $\begin{array}{c}101 \cdot 3(1 \cdot 9) \\
20 \cdot 3(1 \cdot 2)^{\star \star \star} \\
20 \cdot 5(1 \cdot 2)^{\star \star \star} \\
2 \cdot 1(1.9)\end{array}$ \\
\hline $\begin{array}{l}\text { Baseline heart rate } \\
\text { Change b-1 } \\
\text { Change b-2 } \\
\text { Change 1-2 }\end{array}$ & $\begin{aligned} & 67 \cdot 5(1 \cdot 7) \\
+ & 10 \cdot 8(2 \cdot 3)^{\star \star \star} \\
+ & 9 \cdot 1(2 \cdot 6)^{\star \star} \\
- & 0 \cdot 1(1 \cdot 6)\end{aligned}$ & $\begin{aligned} & 64 \cdot 8(1.7) \\
+ & 12 \cdot 0(2 \cdot 5)^{\star \star \star} \\
+ & 7.6(1.7)^{\star \star \star} \\
- & 0.5(1.4)\end{aligned}$ & $\begin{array}{l}66 \cdot 2(2 \cdot 1) \\
+5 \cdot 8(2 \cdot 0)^{\star} \\
+4 \cdot 9(1 \cdot 9)^{\star} \\
-0.5(1 \cdot 7)\end{array}$ \\
\hline
\end{tabular}

${ }^{\star} \mathrm{p}<0.05,{ }^{\star \star} \mathrm{p}<0.01,{ }^{\star \star \star} \mathrm{p}<0.001$. There was no significant difference in the changes between the groups.

Abbreviations as for table $4, \mathrm{~b}-2$, baseline to two minutes, $1-2$, one to two minutes.

Table 6 Mean (SEM) responses to two minute isometric handgrip

\begin{tabular}{|c|c|c|c|}
\hline & Group 1 & Group 2 & Controls \\
\hline No of patients & 25 & 25 & 21 \\
\hline $\begin{array}{l}\text { Baseline FBF } \\
\text { Change b-1 }(\%) \dagger \\
\text { Change b-2 }(\%) \\
\text { Change } 1-2(\%) \ddagger\end{array}$ & $\begin{aligned} & 3 \cdot 7(0 \cdot 4) \\
+ & 79 \cdot 3(10)^{\star \star \star} \\
+ & 75 \cdot 3(10)^{\star \star \star} \\
& -1 \cdot 2(3 \cdot 5)\end{aligned}$ & $\begin{aligned} & 3 \cdot 7(0 \cdot 4) \\
+ & 47 \cdot 9(8 \cdot 2)^{\star \star \star} \\
+ & 68 \cdot 8(9 \cdot 5)^{\star \star \star} \\
+ & 12(3 \cdot 8)^{\star}\end{aligned}$ & $\begin{aligned} & 3 \cdot 6(0 \cdot 3) \\
+ & 50 \cdot 6(8 \cdot 2)^{\star \star \star} \\
+ & 50 \cdot 4(10 \cdot 3)^{\star \star \star} \\
+ & 1 \cdot 7(4 \cdot 7)\end{aligned}$ \\
\hline $\begin{array}{l}\text { Baseline FVR } \\
\text { Change b-1 (\%)\ } \\
\text { Change b-2 (\%) } \\
\text { Change 1-2 (\%)ף }\end{array}$ & $\begin{array}{l}39 \cdot 9(4 \cdot 1) \\
-34(3 \cdot 2)^{\star \star \star} \\
-30 \cdot 3(3 \cdot 9)^{\star \star \star} \\
+6 \cdot 9(4 \cdot 1)\end{array}$ & $\begin{aligned} & 35 \cdot 1(3 \cdot 3) \\
-19 \cdot 7(4 \cdot 0)^{\star \star \star} & -28 \cdot 7(3 \cdot 9)^{\star \star \star} \\
- & 7 \cdot 9(3 \cdot 3)^{\star}\end{aligned}$ & $\begin{aligned} & 31 \cdot 9(2 \cdot 6) \\
- & 23 \cdot 8(4 \cdot 3)^{\star \star \star} \\
- & 21 \cdot 5(4 \cdot 6)^{\star \star} \\
+ & 10 \cdot 4(5 \cdot 6)\end{aligned}$ \\
\hline $\begin{array}{l}\text { Baseline MAP } \\
\text { Change b-1 }(\%) \\
\text { Change b-2 }(\%) \\
\text { Change } 1-2\end{array}$ & $\begin{array}{l}106.8(2.5) \\
+11.3(1.3)^{\star \star \star} \\
+12.9(1.3)^{\star \star \star} \\
+1.6(1.2)\end{array}$ & $\begin{array}{l}105 \cdot 2(2 \cdot 2) \\
+9 \cdot 1(1 \cdot 2)^{\star \star \star} \\
+11 \cdot 5(1 \cdot 3)^{\star \star \star} \\
+0 \cdot 4(0 \cdot 9)\end{array}$ & $\begin{array}{l}101 \cdot 1(2 \cdot 0) \\
+9 \cdot 1(1 \cdot 2)^{\star \star \star} \\
+13 \cdot 8(1 \cdot 3)^{\star \star \star} \\
+3.9(0 \cdot 8)^{\star \star \star}\end{array}$ \\
\hline $\begin{array}{l}\text { Baseline heart rate } \\
\text { Change b-1 (\%) } \\
\text { Change b-2 (\%) } \\
\text { Change } 1-2(\%)\end{array}$ & $\begin{aligned} 68 \cdot 9(1 \cdot 9) \\
+13 \cdot 0(3 \cdot 5)^{\star \star \star} \\
+9 \cdot 8(2 \cdot 1)^{\star \star \star} \\
0(1 \cdot 7)\end{aligned}$ & $\begin{array}{l}66 \cdot 6(2 \cdot 1) \\
+8 \cdot 1(2 \cdot 2)^{\star \star} \\
+7 \cdot 6(1 \cdot 7)^{\star \star} \\
-0.5(1 \cdot 4)\end{array}$ & $\begin{array}{l}68 \cdot 3(1 \cdot 6) \\
+8 \cdot 0(1 \cdot 3)^{\star \star \star} \\
+11 \cdot 6(1 \cdot 6)^{\star \star} \\
+3 \cdot 1(1 \cdot 1)\end{array}$ \\
\hline
\end{tabular}

${ }^{\star} \mathrm{p}<0.05,{ }^{\star \star} \mathrm{p}<0.01,{ }^{\star \star \star} \mathrm{p}<0.001$

$\mathrm{p}<0.02$ between group 1 and 2 , and $\mathrm{p}<0.04$ between group 1 and controls.

$\neq \mathrm{p}<0.02$ between group 1 and 2 , and $\mathrm{p}<0.03$ between group 2 and controls.

$\mathrm{p}<0.01$ between group 1 and 2 .

Ip $<0.01$ between group 1 and 2 and $p<0.01$ between group 2 and controls

Abbreviations as for tables 4 and 5 .

significantly in the first minute of cold immersion (table 5). Between the first and second minute, FBF increased significantly (except in group 2) and FVR decreased significantly in each group. Mean arterial pressure and heart rate remained unchanged between the first and second minute. The changes in the values did not differ significantly between the groups.

\section{ISOMETRIC HANDGRIP TEST}

In the first minute of isometric handgrip, $\mathrm{FBF}$, mean arterial pressure, and heart rate increased and FVR decreased significantly in the three groups (table 6 and figure). In group 1, the increase in FBF was significantly greater than in group $2(p<0.02)$ and in the controls $(p<0.04)$. The decrease in FVR in the first minute was significantly greater in group 1 than group $2(\mathrm{p}<0.001)$. The mean arterial pressure and heart rate changes in the first minute were similar in the three groups.

Between the first and second minute, FBF and FVR remained unchanged in group 1 and the controls, but in group $2, \mathrm{FBF}$ increased further $(\mathrm{p}<0.02)$ and FVR decreased further $(p<0.03)$. In the three groups, heart rate remained unchanged and mean arterial pressure increased only in the controls $(p<0.0001)$ between the first and second minute.

Overall up to two minutes, the changes in FBF, FVR, mean arterial pressure, and heart rate did not differ significantly between the groups.

DIFFERENCES IN AUTONOMIC FUNCTION IN PURE SILENT ISCHAEMIA

Four patients from group 1 had pure silent ischaemia, and the remaining 21 either had a history of angina, or a painful myocardial infarction and a subsequent silent or symptomatic positive exercise test. The autonomic responses to the Valsalva, LBNP, cold pressor, and isometric handgrip tests were compared between these two subgroups of group 1. The Valsalva ratios were not significantly different between the two subgroups. The decrease in FVR during LBNP was significant (table 7) in the group with pure silent ischaemia but the magnitude of change was not significantly different from the remaining patients with silent ischaemia or the controls. The changes in FBF and FVR during one minute of hand grip and the cold pressor test were not significant in the subgroup with pure silent ischaemia. After one minute of the cold pressor test FBF fell non-significantly $(p<0.0001)$. In the group with pure silent ischaemia, but in the remaining patients it decreased significantly $(p<0.0001)$. In the group with pure silent ischaemia, FVR increased non-significantly (by $100.9 \%$ $(88.0 \%))$. In the remaining patients in group 1 the increase of $143.0 \%(32.5 \%)$ was significant $(\mathrm{p}<0.005)$.

After one minute of isometric handgrip in the patients with pure silent ischaemia, FBF increased by $36.9 \%(12.6 \%$, NS). In the remaining patients, FBF increased by $87.4 \%$ $(10.8 \%, \mathrm{p}<0.0001)$. The FVR decreased non-significantly in the group with pure silent ischaemia (by $19 \cdot 2 \%(9.0 \%)$ ), and significantly in the remaining patients in group 1 (by $36 \cdot 8 \%(3 \cdot 2 \%), \mathrm{p}<0.0001)$.

The increase in FBF between baseline and one minute of isometric hand grip in the remaining patients in group 1 was significantly different from that of the controls $(p<0.01)$. When the remaining patients 
Group 1
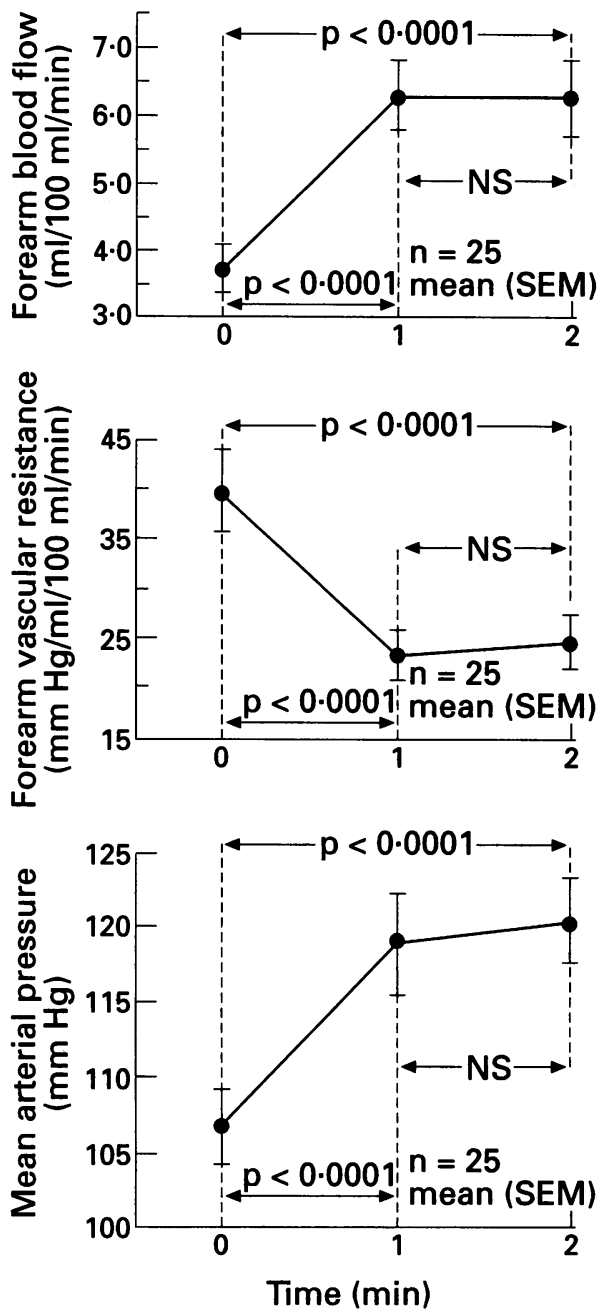

Group 2
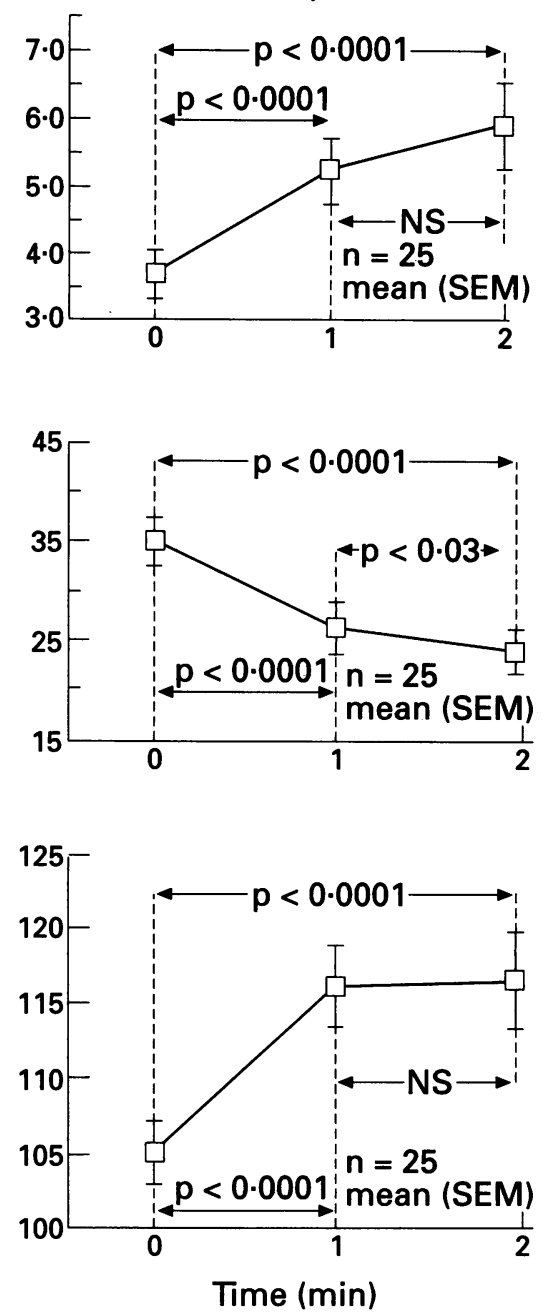

Controls
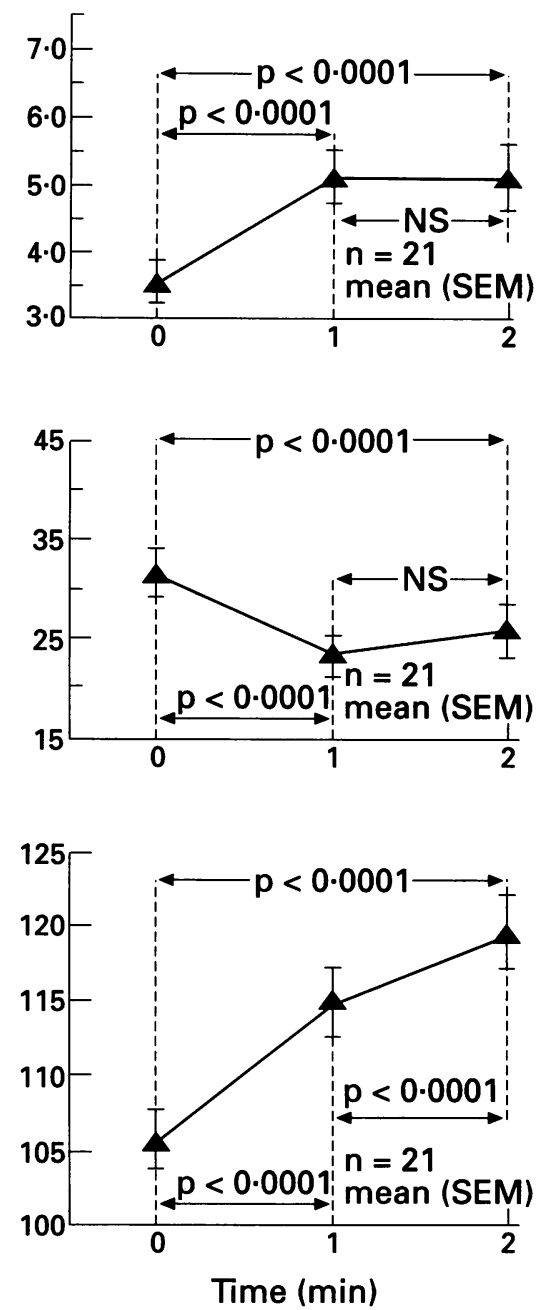

Haemodynamic changes during two minutes of isometric handgrip.

were compared with the whole of group 2, there was no difference in the responses to $-10 \mathrm{~mm} \mathrm{Hg} \mathrm{LBNP}$, cold pressor test, or the Valsalva manoeuvre. During isometric handgrip, however, the mean increase in FBF

Table 7 Mean (SEM) autonomic responses in patients with pure silent ischaemia (pure SI) compared with the remaining patients with silent ischaemia in group 1

\begin{tabular}{|c|c|c|}
\hline & Pure SI & $\begin{array}{l}\text { Remaining } \\
\text { patients }\end{array}$ \\
\hline No of patients & 4 & 21 \\
\hline Valsalva ratio & $1.37(0.08)$ & $1.23(0.04)$ \\
\hline $\begin{array}{l}\text { Lower body negative } \\
\text { pressure: } \\
\text { Baseline FBF } \\
\text { Change in FBF (\%)† } \\
\text { Baseline FVR } \\
\text { Change in FVR (\%) }\end{array}$ & $\begin{array}{c}4 \cdot 5(1 \cdot 0) \\
-33 \cdot 1(10 \cdot 5) \\
29 \cdot 2(10 \cdot 0) \\
+64 \cdot 5(28 \cdot 3)^{\star}\end{array}$ & $\begin{array}{c}4 \cdot 1(0 \cdot 5) \\
-21 \cdot 0(10 \cdot 9)^{\star} \\
33 \cdot 4(4 \cdot 8) \\
+71 \cdot 0(19 \cdot 2)^{\star \star}\end{array}$ \\
\hline $\begin{array}{l}\text { Cold pressor test: } \\
\text { Mean baseline FBF } \\
\text { Change in FBF (\%) } \\
\text { Baseline FVR } \\
\text { Change in FVR (\%) }\end{array}$ & $\begin{array}{c}3 \cdot 4(0 \cdot 8) \\
-3 \cdot 6(34) \\
37 \cdot 0(7 \cdot 6) \\
+100 \cdot 9(88 \cdot 0)\end{array}$ & $\begin{array}{c}3 \cdot 2(0 \cdot 3) \\
-36 \cdot 9(6 \cdot 3)^{\star \star \star} \\
41 \cdot 7(4 \cdot 2) \\
+143 \cdot 0(32 \cdot 5)^{\star \star}\end{array}$ \\
\hline $\begin{array}{l}\text { Isometric handgrip: } \\
\text { Baseline FBF } \\
\text { Change in FBF (\%) } \\
\text { Baseline FVR† } \\
\text { Change in FVR (\%) }\end{array}$ & $\begin{array}{c}4 \cdot 4(1 \cdot 2) \\
+36 \cdot 9(12 \cdot 6) \\
33 \cdot 2(12 \cdot 8) \\
-19 \cdot 2(9 \cdot 0)\end{array}$ & $\begin{array}{c}3 \cdot 6(0 \cdot 4) \\
+87 \cdot 4(10 \cdot 8)^{\star \star \star} \\
32 \cdot 7(4 \cdot 3)^{\star \star \star} \\
-36 \cdot 8(3 \cdot 2)^{\star \star \star}\end{array}$ \\
\hline
\end{tabular}

between baseline and one minute in the remaining patients was greater than that of group $2(p<0.02)$. The decrease in FVR from baseline to one minute of handgrip in the remaining patients was also significantly greater than that of group $2(p<0.004)$.

\section{Discussion}

Patients with silent ischaemia showed a greater forearm vasodilator response after one minute of isometric handgrip than either symptomatic patients or controls. Symptomatic patients had a slower vasodilator response than either patients with silent ischaemia or controls, achieving maximal vasodilatation only after two minutes of handgrip. The cold pressor test indicated no differences between the groups in $a$ mediated peripheral vasoconstriction or cardiac $\beta_{1}$ mediated changes in heart rate. The LBNP test indicated that cardiac parasympathetic afferent function was similar in the groups. The trend towards a greater Valsalva ratio and significantly greater heart variation in the controls compared with both ischaemic groups, suggests impaired parasympathetic efferent function in the ischaemic groups.

Patients in group 1 were classified by 
Holter monitoring criteria as having silent ischaemia. Further evidence to support this is suggested by the fact that exercise testing was silent in 17 out of 24 patients with a positive exercise test. Also, in 16 out of 22 patients in group 1 with a positive thallium scan, the exercise perfusion defects were silent. This would indicate that patients in group 1 are likely to be in a silent ischaemic group by exercise and scintigraphic assessment as well as Holter monitoring.

Several factors that may have affected the results of our study need to be excluded. Hypertension affects autonomic function, causing exaggerated vasoconstrictor responses to cold immersion, ${ }^{17}$ attenuated LBNP responses, ${ }^{16}$ and blunted vasodilator responses to isometric handgrip. ${ }^{19}$ In our study only mildly hypertensive patients were included, with similar numbers in both ischaemic groups. The similarity of cold pressor and LBNP responses between the groups suggests that the hypertensive component of both ischaemic groups was unlikely to have affected the results.

Although chronic with $\beta_{1}$ blockers treatment is thought to result in up regulation of $\beta$ receptors, ${ }^{21}$ recent evidence from Hall et al suggests that treatment of human atrial myocardium with the $\beta_{1}$ blocker atenolol resulted in increased cardiac $\beta_{2}$ activity. ${ }^{22}$ This would result in an enhanced ability to vasodilate in the symptomatic group who had been on $\beta$ blockers (nearly all took atenolol). Indeed, this was not the case, as the patients with silent ischaemia had a significantly greater propensity to vasodilate during isometric handgrip than the symptomatic patients. More recently Hall et al showed that withdrawal from $\beta$ blockers does not result in changes in peripheral vascular vasodilator $\left(\beta_{2}\right)$ activity (JA Hall, personal communication)

There was a trend towards a greater duration of exercise tests, as expected in the silent ischaemic group. The severity of ischaemic heart disease in groups 1 and 2 was, however, similar based on exercise, thallium scintigraphic, and angiographic criteria, and was thought to represent moderately severe disease. ${ }^{23}$ This is expected as it is claimed that ambulatory ischaemia is only likely to be detected in at least moderately severe disease. $^{24} 25$ Ambulatory ischaemia was not used to compare severity of disease as others have shown up to $36 \%$ variation in frequency and $51 \%$ in duration of ischaemic episodes in 24 hour monitoring. ${ }^{26}$

\section{CARDIAC PARASYMPATHETIC FUNCTION}

Our results confirm previous findings of impaired parasympathetic efferent function in patients with ischaemic heart disease. ${ }^{27} 28 \mathrm{We}$ have shown, however, that there was no difference in efferent function between patients with silent and symptomatic ischaemia. Recent evidence suggests that patients with ischaemic heart disease have a higher risk of ventricular arrhythmia and sudden death after myocardial infarction in the presence of impaired parasympathetic efferent function. ${ }^{29}$ If this is the case, then one could speculate that patients with silent ischaemia are no less at risk of these sequelae than symptomatic patients.

In animals, others have previously shown that myocardial ischaemia can stimulate both sympathetic $^{30-32}$ and parasympathetic cardiac afferents. ${ }^{33}$ Ischaemic stimulation of sympathetic afferents has been shown to reduce the threshold of ventricular fibrillation, providing a possible mechanism for arrhythmogenesis. ${ }^{34}$ Furthermore, Schwartz et al showed that cardiac parasympathetic afferent stimulation reduces sympathetic efferent activity, which theoretically could reduce the risk of arrhythmogenesis. The fact that there was no difference in cardiac parasympathetic afferent function between the silent and symptomatic ischaemic groups and controls suggests that they are unlikely to be involved in the prevention of ventricular arrhythmia (by modulating sympathetic efferent activity) in patients with ischaemic heart disease. To examine this further, however, cardiac parasympathetic afferent function should be studied in patients with and without ventricular arrhythmia after myocardial infarction.

\section{CARDIAC SYMPATHETIC FUNCTION}

Previous studies have shown a higher incidence of silent ischaemia in patients with diabetes mellitus and autonomic neuropathy ${ }^{910}$ but failed to identify the type of neuropathy. Our findings suggest that rather than reduced autonomic responses, patients with silent ischaemia had an enhanced autonomic response because of increased forearm vasodilation. This is likely to reflect the composition of the silent ischaemic group. In patients with pure silent ischaemia generalised sympathetic dysfunction was shown with non-significant responses to handgrip and cold immersion compared with controls and the remaining patients in group 1 . In these patients with pure silent ischaemia, a neuropathy would be anticipated as they had never experienced chest pain. In the remaining patients (most of group 1) a neuropathy would perhaps not be anticipated as the patients had experienced angina previously. Some patients with silent ischaemia had a previous myocardial infarction. Such patients may have had intact pain pathways that were disrupted by the infarction process.

There is some controversy over the mechanism of vasodilation during isometric handgrip. Eklund and Kaijser previously showed that the initial handgrip response is due to sympathetic $\beta_{2}$ vasodilatation. ${ }^{12}$ More recently, Sanders et al showed that the response was mediated through cholinergic vasodilation. ${ }^{13}$

Although the overall two minute FBF responses during handgrip did not differ significantly between the groups, the greater initial response within the first minute in the silent ischaemic group may account for the absence of anginal symptoms in myocardial ischaemia. Whatever the mode of the vasodilatation induced by handgrip, it could provide a mechanism for silent ischaemia in patients with intact pain pathways (the remaining patients with silent ischaemia). Although in 
our study the vasodilator response was measured plethysmographically in the peripheral vasculature, coronary vasodilatation in response to handgrip has been previously reported in healthy coronary arteries. ${ }^{35}$ Animal studies have also shown that stimulation of $\beta_{1}$ and $\beta_{2}$ adrenoreceptors results in coronary vasodilatation. ${ }^{36}$ If the mechanism for vasodilation is mediated by $\beta_{2}$ adrenoreceptors as Eklund and Kaijser claim, greater vasodilatation in the coronary vasculature may limit myocardial ischaemia to below the anginal threshold in patients with silent ischaemia. Such a premise would require episodes of silent ischaemia to represent a less severe form of ischaemia, and there is evidence to support this. ${ }^{37}$ If, however, the ischaemic stimulus exceeded the initial time period of vasodilatation, then an ischaemic episode would be symptomatic. If this were the case, then silent ischaemic episodes would be expected to be shorter in duration than symptomatic episodes, and there is evidence to support this too. ${ }^{37}$ Such a model takes no account of other factors such as the intensity of myocardial ischaemic stimulus, but a greater initial propensity to vasodilate may also limit the extent of a more intense ischaemic stimulus.

The patients with symptoms showed a slower vasodilator response to handgrip than either the patients with silent ischaemia or the controls, although the maximal vasodilator response at two minutes was similar in all three groups. In these patients it could be argued that if the slower vasodilator response also occurred in the coronary arteries, this would not limit the onset of ischaemia and pain.

The greater limitation of this study is that sympathetic afferent dysfunction could not be assessed directly, despite generalised sympathetic dysfunction being shown in the patients with pure silent ischaemia. Recently, we have shown that coronary balloon angioplasty can be used to assess cardiac sympathetic afferent activity in humans. ${ }^{38}$ This could be applied in suitable patients with silent ischaemia to determine whether there is evidence of sympathetic afferent dysfunction.

In conclusion, patients with pure silent ischaemia have evidence of generalised sympathetic dysfunction. Patients with silent ischaemia but with pain pathways presumed to be intact have a greater propensity to vasodilate peripherally. If this propensity applies to the coronary vasculature, it could provide a mechanism to limit myocardial ischaemia below the pain threshold. None of the tests directly examine sympathetic afferent nerves that are supposed to convey angina, but we hope that further studies of sympathetic responses to coronary balloon inflation in patients with silent ischaemia will resolve this.

We thank the Nuclear Medicine Department for reporting the thallium scintigrams. CS was supported by a British Heart Foundation junior fellowship.

1 Berkley HJ. The intrinsic nerve supply of the cardiac ventricles in certain vertebrates. Fournal of fohns Hopkins Hospital Reports 1894;4:248-78.
2 Edgeworth FH. On a large fibred sensory supply of the thoracic and abdominal vicera. $\mathcal{F}$ Physiol 1894;13: 260-9.

3 Bishop VS, Malliani A, Thoren P. Cardiac mechanoreceptors. In: Shepherd JT, Abboud F, eds. Handbook of physiology: the cardiovascular system. Bethesda: American Physiological Society 1983;III(2);497-555.

4 Coleridge HM, Coleridge JC. Cardiovascular afferents involved in regulation of peripheral vessels. Ann Rev Physiol 1980;42:413-27.

5 Schwartz P, Pagani M, Lombardi F, Malliani A, Brown AM. A cardiocardiac sympathetovagal reflex in the cat. Circ Res 1973;32:21.5-20.

6 White JC. Cardiac pain, anatomical pathways and physiologic mechanisms. Circulation 1957;16:644-55.

7 Sheps D, Heiss G. Sudden death and silent myocardial ischaemia. Am Heart 7 1989;117:177-84.

8 Droste C, Greenlee M, Roskamm H. Experimental pain measurements in patients with asymptomatic myocardial ischaemia. $f$ Am Coll Cardiol 1983;1:940-5

9 Faerman I, Faccio E, Milei J. Autonomic neuropathy and painless myocardial infarction in diabetic patients. Diabetes 1977;26:1147-58.

10 Langer A, Freeman M, Josse R, Steiner G, Armstrong P. Detection of silent myocardial ischaemia in diabetes mellitus. Am f Cardiol 1991;67:1073-8.

11 Ewing DJ, Clarke B. Diagnosis and management of diabetic autonomic neuropathy. $\mathrm{Br} \mathrm{Med} \mathcal{F}$ 1982;285:916-8.

12 Eklund B, Kaijser L. Effects of regional alpha and beta blockade on blood flow in the resting forearm during contralateral isometric handgrip. If Physiol 1976;262: $39-50$.

13 Sanders JS, Mark AL, Ferguson DW. Evidence for cholinergically mediated vasodilation at the beginning of isometric exercise in humans. Circulation 1989:79:815-24.

14 Zoller R, Mark A, Abboud F, Schmid P, Heistad D. The role of low pressure baroreceptors in reflex vasoconstrictor responses in man. $\mathcal{F}$ Clin Invest 1972;51:2967-72.

15 Wolthius RA, Bergman SA, Nicogossian AE. Physiological effects of locally applied reduced pressure in man. Physiol Rev 1974;54:566-94.

16 Mark A, Mancia G. Cardiopulmonary baroreflexes in humans. In: Shepherd JT, Abboud F, eds. Handbook of physiology: the cardiovascular system. Bethesda: American Physiological Society 1983;III(2);795-813.

17 Hines E, Brown G. The cold pressor test for measuring the reactability of the blood pressure; data concerning 571 normal and hypertensive subjects. Am Heart $\mathcal{f}$ 1936;11:1-9.

18 Nabel E, Ganz P, Gordon J, Alexander R, Selwyn A. Dilation of normal and constriction of atherosclerotic coronary arteries caused by the cold pressor test. Circulation 1988;77:43-52.

19 Nuri M. Forearm vascular dynamics in health and disease. London: University of London, 1985. (Thesis.)

20 Greenfield A, Patterson G. The effects of small degrees of venous distension on the apparent rate of blood inflow to the forearm. F Physiol 1954;125:525.

21 Pritchard $B$, Tomilson B, Walden $R$, Bhattachariee $P$ The beta adrenergic blockade withdrawal phenomenon The beta adrenergic blockade withdra

22 Hall IA Kauman A Brown MI. Selective beta-1 adrenoreceptor blockade enhances positive inotropic responses to endogenous catecholamines mediated through beta-2 adrenoceptors in human atrial myocardium. Circ Res 1990;66:1610-23.

23 Cohn K, Kamm B, Feteih N, Brand R, Goldschlager N. The use of treadmill score to quantify ischaemi response and predict the extent of coronary disease. Circulation 1979;59:286-96.

24 Campbell S, Barry J, Rocco M, Nabel E, Mead-Walters K, Rebecca G, Selwyn A. Features of the exercise test that reflect the activity of ischaemic heart disease out of hospital. Circulation 1986;74:72-80.

25 Quyyumi A, Mockus L, Wright C, Fox KM. Morphology of ambulatory ST segment changes in patients with varying severity

26 Tzivoni D, Gavish A, Benhorin J, Banai S, Keren A, Stern S. Day to day variability of myocardial ischaemic episodes in coronary artery disease. Am $₹$ Cardiol 1987; 60:1003-5.

27 Airaksinen $K$, Ikaheimo $M$, Linnaluoto $M$, Niemela $M$, Takkunen J. Impaired vagal heart rate control in coronary artery disease. Br Heart $\mathcal{f}$ 1987;58:592-7.

28 Tristani F, Kanper D, McDermot D, Peters B, Smith J. Alterations of postural and Valsalva responses in coroAlterations of postural and Valsalva responses in

29 Farrell T, Paul V, Cripps T, Malik M, Bennett E, Ward D, Camm AJ. Baroreceptor sensitivity and electrophysiological correlates in patients after acute myocardial infarction. Circulation 1991;83:945-52.

30 Brown AM. Excitation of afferent cardiac sympathetic nerve fibres during myocardial ischaemia. If Physiol 1967;190:35-53.

31 Uchida Y, Murao S. Excitation of afferent cardiac sympathetic nerve fibres during coronary occlusion. $\mathrm{Am} \mathcal{F}$ Physiol 1974;226:1094-9.

32 Malliani AM, Schwartz P, Zanchetti A. A sympathetic reflex elicited by experimental coronary occlusion. $A m \mathcal{F}$ Physiol 1969;217:703-9.

33 Thoren P. Activation of left ventricular receptors with nonmedullated vagal afferent fibres during occlusion of a coronary artery in the cat. Am $\mathcal{f}$ Cardiol 1976;37: 1046-51. 
34 Kliks BR, Burgess $M$, Abildskov J. Influence of sympathetic tone on ventricular fibrillation threshold during experimental coronary occlusion. Am f Cardiol 1975;36: 45-9.

35 Brown G, Lee A, Bolson E, Dodge H. Reflex constriction of significant coronary stenosis as a mechanism contributing to ischaemic left ventricular dysfunction during isometric exercise. Circulation 1984; 70:18-24.

36 Vatner S, Hintze T, Macho P. Regulation of large coronary arteries by beta adrenergic mechanisms in the conscious dog. Circ Res 1982;51:56-66.

37 Chierchia S, Lazzari M, Freedman B, Brunelli C, Maseri A. Impairment of myocardial perfusion and function during painless myocardial ischaemia. $\mathcal{F} \mathrm{Am}$ Coll Cardio 1983;1:924-30.

38 Shakespeare CF, Crowther A, Cooper IC, Katritsis D, Coltart DJ, Webb-Peploe MM. Autonomic reflexes initiated by balloon angioplasty [abstract]. Circulation $1991 ; 84($ II $): 268$
Department of

Cardiology and

Cardiovascular

Surgery, Royal

Hospital, Muscat,

Sultanate of Oman

R Shahrabani

R Chakraborty

J Valliathu

Correspondence to

Dr Rashid M Shahrabani,

Department of Cardiology,

Royal Hospital,

P. O. Box 1331 Seeb,

Sultanate of Oman.

Accepted for publication

20 September 1993

\section{Cross sectiona}

echocardiograms in the

long axis parasternal view

showing $(A)$ a dilated,

unruptured aneurysm of

the right sinus of Valsalva

dissecting into the upper

part of interventricular

septum and $(B)$ complete

obliteration of the

aneurysm in the

interventricular septum

after operation.

$A O$, aorta; $L V$, left

ventricle; RCS, right

coronary sinus; $R V$, right

ventricle.

\title{
Acute pulmonary oedema: an unusual clinical presentation of unruptured sinus of Valsalva
}

\author{
Rashid Shahrabani, Rabindranath Chakraborty, John Valliathu
}

A 24-year-old man was admitted with a 5 -day history of giddiness, a cough with whitish expectoration, breathlessness, and orthopnoea. The patient showed no marfanoid features. He was afebrile but dyspnoeic. His pulse (40 beats/min) was regular and he showed raised jugular venous pulsation with visible cannon waves. Blood pressure was $130 / 60 \mathrm{~mm} \mathrm{Hg}$. At auscultation an early diastolic murmur (grade 2/6) was heard at the lower sternal edge. An electrocardiogram showed complete heart block, and a chest $x$ ray taken with portable equipment showed cardiomegaly and frank pulmonary oedema. All haematological and biochemical variables were normal. Three blood cultures were negative. Cross sectional
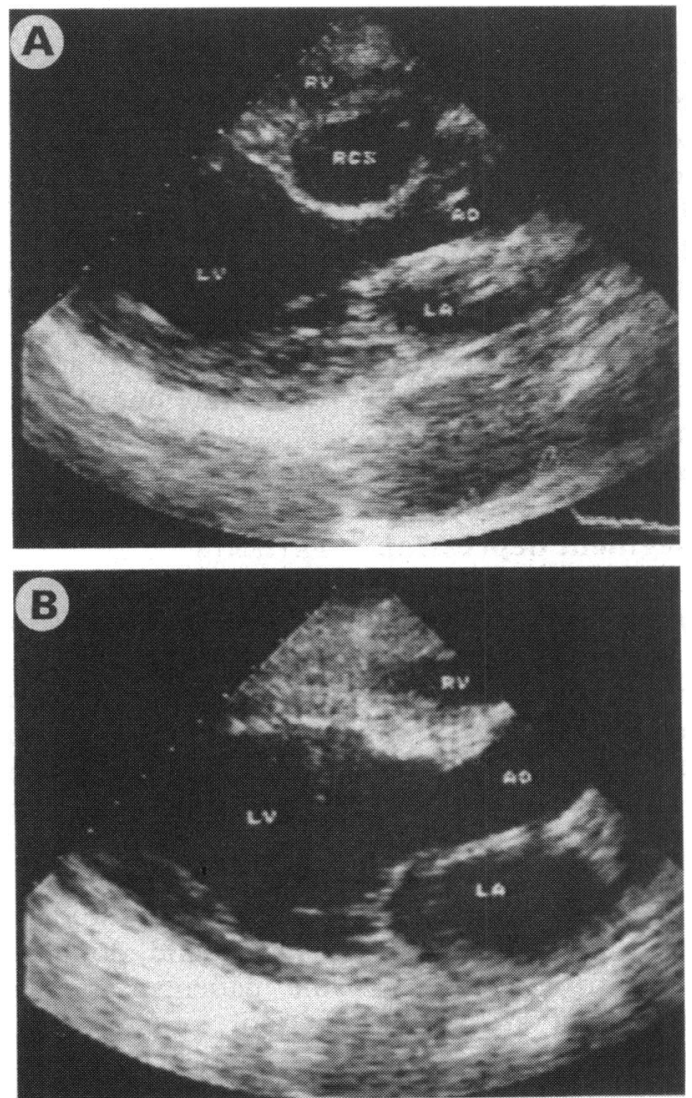

echocardiography confirmed the diagnosis of a dilated, unruptured aneurysm of the right coronary sinus dissecting into the interventricular septum and producing a cystic mass (fig A). Cardiac catheterisation confirmed the presence of an unruptured aneurysm of the right sinus of Valsalva dissecting into the upper part of the interventricular septum with grade $2 / 6$ aortic regurgitation. There was no gradient across the outflow tract. The results of selective coronary angiography were normal.

The patient was treated for heart failure with intravenous frusemide and supplementary potassium and a transvenous temporary pacing wire was inserted. He underwent cardiopulmonary surgery. The ostium of the aneurysm was closed with Dacron patch and a permanent pacemaker was implanted. Postoperatively cross sectional echocardiography showed signs of mild aortic regurgitation. The cystic cavity in the septum had been completely obliterated (fig B).

Unruptured aneurysm of sinus of Valsalva is a rare anomaly that commonly affects the right coronary sinus. ${ }^{1}$ The aneurysm may present clinically as aortic regurgitation ${ }^{2}$ or as a mediastinal mass, ${ }^{3}$ cerebrovascular accident, ${ }^{4}$ or complete heart block. ${ }^{5}$ Some patients have presented with dyspnoea on exertion (NYHA functional class II)..$^{56}$ Our patient was orthopnoeic (NYHA functional class IV) with clinical and radiological features of frank pulmonary oedema. His condition improved considerably after successful surgical repair.

1 Fisbein MC, Obma R, Roberts WC. Unruptured sinus of Valsalva aneurysm. Am f Cardiol 1975;24:918-22.

2 London SB, London RE: Production of aortic regurgitation by unperforated aneurysm of sinus of Valsalva. Circulation 1961;24:1403-6.

3 Reid PG, Goudevenos JA, Hilton CJ. Thrombosed saccular aneurysm of a sinus of Valsalva: Unusual cause of a mediastinal mass. Br Heart $\mathcal{F} 1990 ; 63: 183-5$.

4 Shahrabani R, Jairaj PS. Unruptured aneurysm of the sinus of Valsalva: a potential source of cerebrovascular embolism. Br Heart $\mathcal{f}$ 1993;69:266-7.

5 Ahmed RAS, Struman S, Watson RDS. Unruptured aneurysm of the sinus of Valsalva presenting with isolated heart block: echocardiographic diagnosis and successful surgical repair. Br Heart $\mathcal{f} 1989 ; 61: 375-7$.

6 Metras D, Coulibaly AO, Ouattara K. Calcified unruptured aneurysm of sinus of Valsalva with complete heart block and aortic regurgitation. Br Heart $\mathcal{f}$ 1982;48: 507-9. 